\title{
Analisis Pendapatan Usahatani Padi (Oriza Sativa L.) Sawah di Sekitar dan Bukan Sekitar Tambang Batu Bara di Desa Kerta Buana Kecamatan Tenggarong Seberang Kabupaten Kutai Kartanegara
}

\author{
Tri Pamungkas A.S ${ }^{1}$, Tetty Wijayanti ${ }^{2}$, dan Nike Widuri ${ }^{3}$ \\ 1,2,3 Fakultas Pertanian Universitas Mulawarman, Gn. Kelua, Kec. Samarinda Ulu, Kota \\ Samarinda, Kalimantan Timur \\ 2Email : tettywijayanti_akbar@yahoo.com
}

\begin{abstract}
The existence of coal mines around paddy fields has a negative impact on the level of fertility of paddy fields, because coal mining waste can increase the acidity of paddy fields so that costs are needed to netralize it. The purpose of this study was to campare the income, revenue, profit, ratio of Low Land Paddy Farming in and around the coal mines in the village of Kerta Buana. This research was conducted from to july 2019 in Kerta Buana Village, Tenggarong Subdistrict. The research method in taking this sample by using stratified random sampling with the number of respondents as many as 40, the data analyzed method used with the calculation of income and to make a comparison of income with $t$ test analysis. The results showed that the average production cost of lowland paddy around the mine was Rp9.760.137,78 $\mathrm{mt}^{1}$. Average receipt of $R p 13.417 .800,00 \mathrm{mt}^{1}$. The average income earned is Rp3.657.662,22 $\mathrm{mt}^{1}$. The average production cost of low land paddy not around the minewas Rp12.845.989,67 $\mathrm{mt}^{1}$. Average receipts obtained amounted to Rp22.315.920,00 $\mathrm{mt}^{-1}$. The average income earned is Rp9.469.930,33 $\mathrm{mt}^{1}$. Comparison of income with T-test of Low Land Paddy Farming around and not around coal mine was $t_{\text {count }} 3,525$ while $t$ table $(0, .5)$ emounted to 2.024 so $t$ count $>t$ table $(3.525>$ 2.024) meaning that Ho hypothesis is rejected and hypothesis $\mathrm{Ha}$ accepted. Statistically it can be concluded that the income of wetland paddy was different botom not around coal mine and around coal mine is than lowland paddy farming income around coal mine.
\end{abstract}

Keywords: Ex-mining, Farming, Land Income, Lowland Paddy, Production cost.

\begin{abstract}
ABSTRAK
Keberadaan tambang batu bara di sekitar lahan persawahan menimbulkan dampak negatif terhadap tingkat kesuburan lahan sawah, karena limbah tambang batu bara dapat meningkatkan keasaman lahan sawah sehingga diperlukan biaya untuk menetralkannya. Tujuan penelitian ini adalah untuk megetahui pendapatan, penerimaan, keuntungan, perbandingan usahatani padi sawah di sekitar dan bukan sekitar tambang batubara di desa kerta buana. Penelitian ini dilaksanakan sejak bulan Mei hingga Juli 2019 di Desa Kerta Buana, Kecamatan Tenggarong Seberang. Metode penelitian dalam pengambilan sampel ini dengan menggunakan acak berstrata (stratified random sampling) dengan jumlah responden sebanyak 40, metode analisis data yang digunakan dengan perhitungan pendapatan dan untuk melakukan perbandingan pendapatan dengan analisis uji t. Hasil penelitian menunjukkan rata-rata biaya produksi padi sawah di sekitar tambang sebesar Rp9.760.137,78 $\mathrm{mt}^{-1}$. Penerimaan rata-rata sebesar Rp13.417.800,00 $\mathrm{mt}^{-1}$. Pendapatan rata-rata yang diperoleh sebesar Rp3.657.662,22 $\mathrm{mt}^{-1}$. Rata-rata biaya produksi padi sawah bukan sekitar tambang sebesar Rp12.845.989,67 $\mathrm{mt}^{-1}$. Penerimaan rata-rata yang diperoleh sebesar Rp22.315.920,00 $\mathrm{mt}^{-1}$. Pendapatan rata-rata yang diperoleh sebesar Rp9.469.930,33 $\mathrm{mt}^{-1}$. Perbandingan pendapatan dengan uji-T usahatani padi sawah di sekitar dan bukan sekitar tambang batubara yaitu thitung sebesar 3,525 sedangkan $t$ tabel $(0,05)$ sebesar 2,024 maka $t$ hitung $>t$ tabel (3,525> 2,024) yang berarti bahwa hipotesis Ho ditolak dan hipotesis Ha diterima. Secara statistik dapat disimpulkan bahwa terdapat perbedaan pendapatan usahatani
\end{abstract}


padi sawah sekitar tambang batubara dan usahatani padi sawah bukan sekitar tambang batubara.

Kata Kunci: Biaya produksi, Lahan bekas tambang, Pendapatan, Padi sawah, Usahatani

\section{Pendahuluan}

Pertanian merupakan salah satu sektor ekonomi yang penting kedudukannya di Indonesia, oleh karena itu pertanian Indonesia dengan segala sumber daya yang dimiliki merupakan potensi yang sudah selayaknya dikembangkan. Pembangunan pertanian diarahkan untuk meningkatkan taraf hidup petani, memperluas lapangan pekerjaan, dan keadaan pangan yang relatif dapat ditemui kapan dan dimana saja akan memberi andil yang cukup dalam menjaga stabilitas ekonomi, politik, dan sosial. Pertambahan jumlah penduduk mendorong meningkatnya kebutuhan manusia yang beraneka ragam, oleh karena itu perlu digalakkan usaha peningkatan produksi beras sebagai bahan makanan pokok. Indonesia sudah merintis usaha peningkatan produksi beras sejak Pelita I. Hasilnya cukup menggembirakan dengan tercapainya swasembada beras pada tahun 1984.

Hasil survey Kerangka Sampel Area, luas panen padi di Indonesia dari periode Januari-September tahun 2018 sebesar 9,54 juta hektar. Produksi padi pada tahun 2018 mencapai 49,65 juta ton gabah kering giling (GKG), dengan produktifitas rata-rata 5.2ton/ha. Jika dikonversi ke beras nasioal sebesar 28,47 juta ton dan mengalami surflus produksi beras Januari-Desember sebesar 2,85 juta ton beras.( Badan Pusat Statistik Indonesia, 2018)

Kalimantan Timur memiliki potensi padi sawah yang,luas panen tahun 2018 mencapai 58,15 ribu hektar, dengan tingkat produktifitas rata-rata 3,85 ton/ha dan pada saat ini produksi padidari Januari hingga September 2018 sebesar 241,15 ribu ton gabah kering giling (GKG) jika di konversi ke beras sebesar 139,69 ribu ton namun Kalimantan timur mengalami defisit produksi beras dari Januari-September sebesar 187,9 ribu ton beras.( BPS Kaltim, 2018)

Desa Kerta Buana adalah salah satu desa di Kecamatan Tenggarong Seberang yang memiliki luas wilayah $20,10 \mathrm{~km}^{2} \mathrm{~d}$ engan jumlah penduduk 5.549 jiwa dan 1.548 kepala keluarga, karena sebagian besar penduduknya mempunyai pekerjaan sebagai petani padi sawah dengan jumlah petani padi sawah 367 (Profil Desa Kerta Buana Tenggarong Seberang, 2017). Sebagian besar penduduk bermata pencaharian sebagai petani yang mengusahakan tanaman padi sawah. Selain itu, petani mengusahakan tanaman lain misalnya palawija atau jenis-jenis sayuran. Desa Kerta Buana merupakan sentral tanaman pangan khususnya padi sawah dengan luas persawahan 846 (ha) dengan jumlah produktifitas padi sawah 44,27 (kw/ha) dan produksi padi sawah sebesar 3.745 (ton). Pengembangan tanaman padi sawah mempunyai prospek baik dan 
mendukung peningkatan pendapatan petani, peningkatan gizi masyarakat, perluasan lapangan kerja dan pengembangan agribisnis. Petani dalam pengolahan usahatani umumnya telah mengetahui penggunaan faktor produksi akan tetapi kesederhanaan berfikir kurang dapat memanfaatkan teknologi produksi pertanian, sehinga petani tidak dapat meningkatkan produksinya dan meningkatkan pendapatan (BPS Kutai Kartanegara, 2016).

Peningkatan produksi padi sawah di Desa Kerta Buana tidak bisa lagi dengan cara ekstensifikasi atau perluasan lahan, hal ini karena sebagian lahan yang ada telah berubah fungsi menjadi tambang batu bara, sehinga peningkatan produksi hanya dapat dilakukan dengan cara intensifikasi yaitu suatu cara meningkatkan produksi per hektar sawah dengan meningkatkan penggunaan faktor-faktor produksi seperti tenaga kerja, bibit unggul, pupuk, pestisida, dan pengolahan tanah yang tepat.Penurunan produksi per hektar sawah di Desa Kerta Buana mulai terasa sejak 2011 akibat adanya efek samping dari beroperasinya perusahaan tambang batu bara tahun 2007 . data statistik pada tahun 2007 total produksi Desa Kerta Buana sebesar 6.224 (ton) dari luas lahan 1.218 (ha) dan pada tahun 2011 produksi padi sawah sebasar 4.689 ( ton) dari luas lahan $1.036(\mathrm{Ha})$ untuk mempertahankan produksi padi sawah terpaksa petani menambah biaya khususnya pada pengadaan pupuk karena adanya penambangan batu bara menyebabkan keasaman tanah semakin tinggi. (BPS Kutai Kartanegara, 2007 dan 2011).

Hal ini terjadi karena limbah tambang batubara meresap pada tanah yang langsung bersinggungan dengan sawah akibatnya diperlukan usaha untuk menetralisirkan keasaman tanah yang memakan biaya cukup besar. Selain itu kegagalan panen paling sering terjadi karena padi yang sudah ditanam terpaksa gagal panen karena banjir diakibatkan tanggul yang dibuat perusahaan tambang batu bara jebol. Kesemua ini berdampak pada produksi padi dan pendapatan petani.

Peningkatan produksi padi dengan penggunaan faktor-fakor produksi yang lebih efisien selain membantu kebutuhan masyarakat, dharapkan juga dapat meningkatkan pendapatan petani karena biaya produksi menjadi sedikit, sayangnya dalam kenyataanya jauh berbeda karena untuk mempertahankan produksi padi sawah per hektar diperlukan tambahan biaya produksi yang cukup besar. Oleh karena itu dengan melihat kondisi Desa Kerta Buana yang dikelilingi oleh tambang batu bara maka perlu kiranya konsep pemikiran untuk melihat sampai sejauhmana pendapatan petani dengan adanya tambang batu bara. Berdasarkan uraian tersebut, penelitian ini dilakukan dengan mengambil judul "Analisis Pendapatan Usahatani Padi Sawah (Oriza Sativa L.) di Sekitar Dan Bukan Sekitar Tambang Batubara Di Desa Kerta Buana Kecamatan Tenggarong Seberang Kabupaten Kutai Kartanegara". 


\section{ISSN 2354-7251 (print)}

\section{Metode Penelitian}

Informasi yang didapat dari UPTD Pertanian Tenggarong Seberang tahun 2017, jumlah populasi petani yang aktif melakukan budidaya padi sawah saat ini 367 petani. Besaran sampel yang diambil adalah 40 responden dihitung berdasarkan rumus Slovin (Prasetyo dan Jannah, 2006) sebagai berikut :

$$
\begin{aligned}
& \left(n=\frac{N}{1+N e^{2}}\right) \\
& \left(n=\frac{367}{1+367 \times(15 \%)^{2}}\right) \\
& n=39,64 \\
& n=40
\end{aligned}
$$

Teknik pengambilan sempel adalah probability sampling dengan menggunakan proportionate stratified random sampling. Menurut Sugiyono (2010) proportionate stratified random sampling adalah teknik yang digunakan bila populasi mempunyai atau unsur yang tidak homogen dan berstrata secara proposional. Dengan rumus sebagai berikut :

$$
\left(n i=\frac{N i}{N} \cdot n\right)
$$

Keterangan :

ni = Jumlah sampel

$\mathrm{Ni}=$ Total sub populasi

$\mathrm{N}=$ Total populasi

$\mathrm{n}=$ Besarnya sampel

Tabel 1. Data sampel Desa Kerta Buana.

\begin{tabular}{lllrr}
\hline No & Nama Dusun & \multicolumn{1}{c}{ Lokasi } & Perhitungan & JumlahSampel \\
\hline 1 & Sida karya & Sekitar tambang & $\frac{83}{367} \times 40$ & 9 \\
2 & Budi daya & Sekitar tambang & $\frac{56}{367} \times 40$ & 6 \\
3 & Rapak rejo & Bukan sekiar tambang & $\frac{127}{367} \times 40$ & 14 \\
4 & Rinjani indah & Bukan sekitar tambang & $\frac{101}{367} \times 40$ & 11 \\
& & & 40 \\
\hline \multicolumn{7}{l}{ Jumber : data primer (diolah), 2019 }
\end{tabular}

\section{Total Biaya}

Menurut Amaliawati dan Murni (2014), total biaya adalah total biaya tetap ditambah total biaya variabel. Total biaya secara matematis dapat dirumuskan sebagai berikut:

$$
\mathrm{TC}=\mathrm{TFC}+\mathrm{TVC}
$$


Keterangan :

$$
\begin{array}{ll}
\text { TC } & =\text { Total Cost } \\
\text { TFC } & =\text { Total Fixed Cost atau total biaya tetap } \\
\text { TVC } & =\text { Total variable cost atau total biaya tidak tetap }
\end{array}
$$

\section{Penerimaan}

Penerimaan adalah hasil perkalian antara harga dengan jumlah barang yang diproduksi (Bangun, 2007). Penerimaan secara sistematis dapat dirumuskan sebagai berikut:

$$
\mathbf{T R}=\mathbf{P} \cdot \mathbf{Q}
$$

Keterangan :

$$
\begin{array}{ll}
\mathrm{TR} & =\text { Penerimaan total (total revenue) } \\
\mathrm{P} & =\text { Harga }(\text { price) } \\
\mathrm{Q} & =\text { Jumlah barang (quantity) }
\end{array}
$$

\section{Pendapatan dan R/C Ratio}

Pendapatan adalah total penerimaan dikurangi total biaya yang dikeluarkan selama produksi (Pracoyo, 2006). Pendapatan secara matematis dapat dirumuskan sebagai berikut:

$$
\text { I = TR-TC }
$$

$$
\begin{aligned}
& \text { Keterangan : } \\
& \begin{array}{ll}
\mathrm{I}=\text { Pendapatan }(\text { income }) \\
\text { TR } \quad=\text { Total penerimaan (revenue) } \\
\text { TC } \quad \text { = Total biaya }(\text { cost })
\end{array}
\end{aligned}
$$

Efisiensi adalah Perbandingan antara penerimaan dan biaya di mana penerimaan lebih besar dibandingkan dengan total biaya (Hernanto, 2003). Cara menghitung Analisis Revenue Cost Ratio adalah sebagai berikut:

$$
\mathrm{R} / \mathrm{C} \text { ratio }=\mathrm{TR} / \mathrm{TC}
$$

Keterangan:

$$
\begin{aligned}
& \mathrm{R} / \mathrm{C} \text { ratio }=\text { Perbandingan antara penerimaan dan biaya } \\
& \mathrm{TR} \quad=\text { Total Penerimaan } / \text { Total Revenue }(\mathrm{Rp}) \\
& \mathrm{TC} \\
& =\text { Biaya Total } / \text { Total Cost }(\mathrm{Rp})
\end{aligned}
$$

Keputusan:

$\mathrm{R} / \mathrm{C}$ ratio $>1$ =Berarti usaha yang dilakukan secara ekonomis efisien atau menguntungkan.

$\mathrm{R} / \mathrm{C}$ ratio $<1$ =Berarti usaha yang dilakukan secara ekonomis tidak efisien atau tidak menguntungkan. 


\section{Hasil dan Pembahasan}

Hasil penelitian yang dilakukan di lapangan, responden padi sawah di sekitar tambang batubara sebanyak 15 responden dengan lahan rata-rata seluas 0,75 ha, dan responden padi sawah bukan sekitar tambang batubara sebanyak 25 responden dengan lahan rata-rata seluas 1,08 ha.

\section{Biaya Produksi}

Biaya total yang perhitungan merupakan biaya produksi meliputi biaya tetap (biaya penyusutan alat) dan biaya variabel (biaya benih, biaya pupuk, biaya pestisida, biaya tenaga kerja dan biaya lain-lain).

Biaya Tetap

Biaya Penyusutan alat Biaya penyusutan alat yang di perhitungkan adalah biaya penyusutan alat-alat yang digunakan oleh petani meliputi cangkul, arit, parang, sprayer dan terpal, traktor dan treser. Harga masing-masing alat yang digunakan pada usahatani padi sawah sekitar tambang dan bukan sekitar tambang adalah cangkul Rp60.000,00 parang dengan harga Rp90.000,00 sampai Rp100.000,00 sprayer dengan harga berkisar antara Rp350.000,00 sampai Rp1.500.000,00 arit dengan harga $R p 60.000,00$ sampai Rp75.000,00 untuk harga terpal Rp95.000,00 sampai Rp120.000,00 traktor dengan harga Rp16.000.000,00 sampai Rp21.000.000,00 treser dengan harga Rp4.000.000,00 sampai Rp7.000.000,00 Jumlah biaya penyusutan alat yang dikeluarkan oleh 15 responden padi sawah sekitar tambang batubara dengan rata-rata luas lahan 0,75 ha adalah Rp9.010.500,00 $\mathrm{mt}^{-1}$ dengan rata- rata Rp600.700,00 $\mathrm{mt}^{-1}$ sedangkan jumlah biaya penyusutan alat yang dikeluarkan oleh 25 responden petani padi sawah bukan sekitar tambang batubara dengan luas lahan rata-rata 1,08 ha adalah $\mathrm{Rp} 17,360,250,00 \mathrm{mt}^{-1}$ dengan rata-rata $\mathrm{Rp} 694.410,00 \mathrm{mt}^{-1}$.

Biaya Variabel Total

Biaya Benih

Benih yang digunakan petani padi sawah sekitar tambang dan bukan sekitar tambang batubara di Desa Kerta Buana yaitu IR 64 dan Ciherang. Jumlah benih yang digunakan petani beragam disesuaikan dengan kebutuhan usahataninya. Pada hasil penelitian, harga benih yang digunakan pada usahatani padi sawah dalam penelitian ini adalah sebesar Rp6.500,00 untuk padi lokal dan untuk padi unggul adalah sebesar Rp10.000,00.

Jumlah benih yang digunakan oleh 15 responden padi sawah sekitar tambang batubara dengan luas lahan rata-rata 0,75 ha adalah $317,5 \mathrm{~kg} \mathrm{mt}^{-1}$ dengan rata-rata $21,16 \mathrm{~kg} \mathrm{mt}^{-1}$, jumlah biaya benih yang dikeluarkan adalah Rp2.361.250,00 $\mathrm{mt}^{-1}$ dengan rata-rata $\mathrm{Rp} 157.416,00 \mathrm{mt}^{-1}$. Jumlah benih yang digunakan oleh 25 responden padi 
sawah bukan sekitar tambang batubara dengan luas lahan rata-rata 1,08 adalah 567,00 $\mathrm{kg} \mathrm{mt}^{-1}$ dengan rata-rata $22,68 \mathrm{~kg} \mathrm{mt}^{-1}$, jumlah biaya benih yang dikeluarkan Rp3.685.500,00 $\mathrm{mt}^{-1}$ dengan rata-rata $\mathrm{Rp} 167.300,00 \mathrm{mt}^{-1}$.

Penggunaan benih yang besar menurut responden dikarenakan jarak tanam yang tidak beraturan dan pertambahan benih pada proses penyulaman yang dilakukan untuk mengganti bibit yang tidak tumbuh akibat kerusakan yang disebabkan oleh hama keong mas dan kebusukan serta kurang subur nya tanah akibat limbah yang di sebabkan tambang batu bara.

Biaya Pupuk

Pupuk yang digunakan oleh 40 responden padi sawah di Desa Kerta Bhuana, Urea, NPK, SP-36, Dolomit. Harga masing-masing pupuk tersebut adalah pupuk urea Rp2.000,00 kg-1, pupuk SP-36 Rp2.400,00 kg-1, pupuk NPK Rp2.400,00 kg-1, dolomit $\mathrm{Rp} 1.500,00 \mathrm{~kg}^{-1}$. Jumlah biaya pupuk yang dikeluarkan oleh 15 responden padi sawah sekitar tambang dengan luas lahan rata-rata 0,75 ha adalah $\mathrm{Rp} 19.460 .000,00 \mathrm{mt}^{-1}$ dengan rata- rata $\mathrm{Rp} 1.967 .813,00 \mathrm{mt}^{-1}$, untuk jumlah biaya pupuk yang dikeluarkan oleh 25 responden padi sawah bukan sekitar tambang batubara dengan luas lahan rata-rata 1,08 adalah Rp20.600.000,00 $\mathrm{mt}^{-1}$ dengan rata- rata $\mathrm{Rp} 824.000,00 \mathrm{mt}^{-1}$.

Jumlah biaya pestisida yang dikeluarkan oleh 15 responden padi sawah sekitar tambang batubara adalah Rp16.050.000,00 $\mathrm{mt}^{-1}$ dengan rata-rata Rp1.104.076,92 $\mathrm{mt}^{-1}$ sedangkan jumlah biaya pestisida yang dikeluarkan oleh 25 responden padi sawah bukan sekitar tambang batubara adalah Rp31.395.000,00 $\mathrm{mt}^{-1}$ dengan rata-rata Rp1.255.800,00 $\mathrm{mt}^{-1}$.

Responden sekitar tambang sedikit lebih banyak menggunakan pestisida, jadi petani padi sawah bukan sekitar tambang batubara dapat menghemat biaya yang di keluarakan di biaya pestisida. Sedang untuk pada proses penanaman sampai dengan pemanenan rawan akan adanya terkena hama penyakit.

\section{Biaya Tenaga Kerja}

Biaya tenaga kerja dihitung selama satu musim tanam. Biaya tenaga kerja yang diperhitungkan pada usahatani padi sawah sekitar dan bukan sekitar tambang batubara adalah penyiapan lahan, persemaian, penanaman, pemupukan, penyemprotan, pemeliharaan, panen, dan pasca panen. Upah tenaga kerja yang ada di Desa Kerta Bhuana adalah untuk tenaga kerja Pria, Rp100.000,00 tenaga kerja Wanita Rp80.000,00 HOK meliputi (persemaian, pemupukan, pemeliharaan, penyemprotan dan pasca panen).

Proses penanaman dan panen pada tanaman padi sawah di Desa kerta Buana menggunaan sistem borongan. Untuk borongan tanam adalah sebesar Rp1.500.000,00 ha $^{-1}$ dan untuk borongan panen yaitu dengan sistem bagi hasil 5 banding 1, yang mana yang punya lahan mendapatkan 5 dan menggolah dapat 1 . 
Jumlah biaya tenaga kerja yang dikeluarkan 15 responden padi sawah sekitar tambang batubara dengan rata-rata luas lahan 0,75 ha adalah Rp70.028.816,67 $\mathrm{mt}^{-1}$ dengan jumlah rata- rata Rp4.668.587,78 $\mathrm{mt}^{-1}$, kemudian untuk jumlah biaya tenaga kerja yang dikeluarkan oleh 25 responden padi sawah bukan sekitar tambang batubara dengan rata-rata luas lahan 1,08 ha adalah $\mathrm{Rp} 165.970 .241,67 \mathrm{mt}^{-1}$, dengan rata-rata Rp6.638.809,67 $\mathrm{mt}^{-1}$.

Biaya Lain-lain

Biaya lain-lain yang dimaksud dalam penelitian ini yakni biaya yang dikeluarkan untuk membayar sewa, seperti sewa traktor, theaser, karung dan biaya penggilingan. Biaya-biaya yang dikeluarkan oleh 15 responden padi sawah sekitar tambang batubara dengan jumlah biaya upah Traktor dengan jumlah Rp12.296.000,00 $\mathrm{mt}^{-1}$ dengan rata-rata Rp1.613.785,71 $\mathrm{mt}^{-1}$. Untuk upah Threaser dengan jumlah biaya sebesar Rp2.025.000,00 $\mathrm{mt}^{-1}$ dengan rata-rata sebesar Rp202.500,00 $\mathrm{mt}^{-1}$. Upah jumlah biaya pengilingan yakni sebesar Rp11.480.000,00 $\mathrm{mt}^{-1}$ dengan rata-rata sebesar Rp765.333,00 $\mathrm{mt}^{-1}$. Kemudian untuk upah jumlah biaya karung sebesar Rp3.375.000,00 $\mathrm{mt}^{-1}$ dengan rata-rata sebesar Rp225.000,00 $\mathrm{mt}^{-1}$

Dua puluh lima (25) responden padi sawah bukan sekitar tambang batubara dengan jumlah biaya upah traktor yaitu Rp28.613.500,00 $\mathrm{mt}^{-1}$ dengan rata-rata Rp2.308.730,00 $\mathrm{mt}^{-1}$. Upah threaser dengan jumlah biaya sebesar Rp3.300.000,00 $\mathrm{mt}^{-1}$ dengan rata-rata sebesar $\mathrm{Rp} 300.000,00 \mathrm{mt}^{-1}$. Upah jumlah biaya pengilingan yakni sebesar Rp31.140.000,00 $\mathrm{mt}^{-1}$ dengan rata-rata sebesar Rp1.245.600,00 $\mathrm{mt}^{-1}$, kemudian untuk upah jumlah biaya karung sebesar Rp8.100.000,00 $\mathrm{mt}^{-1}$ dengan rata-rata sebesar Rp324.000,00 $\mathrm{mt}^{-1}$.

Total biaya lain-lain yang dikeluarkan oleh 15 responden padi sawah sekitar sebesar Rp12.296.000,00 dan bukan sekitar tambang batubara sebesar Rp28.613.500,00 $\mathrm{mt}^{-1}$ dengan jumlah rata- rata adalah Rp3.999.266,00 $\mathrm{mt}^{-1}$.

\section{Total Biaya Produksi}

Total biaya adalah jumlah keseluruhan yang di keluarkan oleh petani dalam proses produksi yang dimulai dari biaya benih, biaya pupuk, biaya pestisida, biaya penyusutan alat, biaya tenaga kerja, dan biaya lain- lain. Jumah total yang dikeluarkan oleh 15 responden padi sawah sekitar tambang dimulai dari biaya benih sebesar Rp2.361.250,00 $\mathrm{mt}^{-1}$ dengan jumlah rata-rata sebesar Rp157.416,67 $\mathrm{mt}^{-1}$, kemudian untuk jumlah biaya pupuk sebesar Rp19.460.000,00 $\mathrm{ha}^{-1} \mathrm{mt}^{-1}$ jumlah rata- rata Rp1.297.333,00 $\mathrm{mt}^{-1}$, untuk jumlah keseluruhan yang dikeluarkan untuk biaya pestisida sebesar Rp16.365.000,00 mt $\mathrm{mt}^{-1}$ jumlah rata-rata sebesar Rp1.091.000,00 $\mathrm{mt}^{-1}$ untuk jumlah keseluruhan penyusutan alat adalah sebesar Rp9.010.500,00 $\mathrm{mt}^{-1}$ dengan jumlah ratarata Rp600.700,00 $\mathrm{mt}^{-1}$, kemudian untuk jumlah biaya tenaga kerja adalah sebesar 
Rp70.028.816,67 $\mathrm{mt}^{-1}$ dengan jumlah rata-rata sebesar Rp4.668.587,78 $\mathrm{mt}^{-1}$ dan jumlah biaya lain- lain sebesar Rp29.176.500,00 mt ${ }^{-1}$ jumlah rata-rata $\mathrm{Rp} 1.945 .100,00 \mathrm{mt}^{-1}$. Jadi jumlah total biaya produksi oleh 15 responden padi sawah sekitar tambang yang ada di Desa Kerta Buana sebesar Rp146.402.066,67 $\mathrm{mt}^{-1}$ dan jumlah rata-rata sebesar Rp9.760.137,78 $\mathrm{mt}^{-1}$.

Jumlah biaya yang dikeluarkan keseluruhan oleh 25 responden padi sawah bukan sekitar tambang batubara meliputi, biaya benih, biaya pemupukan, biaya pestisida, biaya penyusutan alat, biaya tenaga kerja dan biaya lain- lain. Total biaya yang pertama adalah biaya benih sebesar Rp4.182.500,00 $\mathrm{mt}^{-1}$ jumlah rata-rata sebesar $\mathrm{Rp} 167.300,00 \mathrm{mt}^{-1}$. Untuk biaya pupuk sebesar Rp20.600.000,00 $\mathrm{mt}^{-1}$ dengan jumlah rata-rata Rp824.000,00 $\mathrm{mt}^{-1}$ jumlah untuk biaya pestisida adalah sebesar Rp31.395.000,00 $\mathrm{mt}^{-1}$ dan jumlah ratarata sebesar Rp1.255.800,00 $\mathrm{mt}^{-1}$ kemudian untuk jumlah biaya penyusutan alat adalah sebesar Rp16.860.000,00 $\mathrm{mt}^{-1}$ jumlah rata-rata sebesar Rp674.400,00 $\mathrm{mt}^{-1}$, untuk biaya tenaga kerja sebesar Rp165.970.241,67 $\mathrm{mt}^{-1}$ dan jumlah rata-rata sebesar Rp6.638.809,67 $\mathrm{mt}^{-1}$ kemudian untuk biaya selanjutnya adalah biaya lain-lain yang dikeluarkan sebesar Rp82.142.000,00 $\mathrm{mt}^{-1}$ dan jumlah rata-rata sebesar Rp3.285.680,00 $\mathrm{mt}^{-1}$. Jadi jumlah keseluruhan dari total biaya yang dikeluarkan oleh 25 responden padi sawah bukan sekitar tambang dalah sebesar Rp321.149.741,67 $\mathrm{mt}^{-1}$ dan jumlah rata-rata adalah Rp12.845.989,67 $\mathrm{mt}^{-1}$.

Penggunaan benih yang digunakan rata-rata oleh petani di Desa Kerta Buana ini adalah benih yang bukan termasuk jenis benih unggul, mengapa demikian karena petani ini menyisihkan beberapa $\mathrm{kg}$ dari setiap hasil panen yang diperoleh dengan melakukan seleksi benih melalui mekanisme perendaman terlebih dahulu yang dilakukakan oleh petani dengan kualiatas yang baik agar dapat memberikan hasil tanaman agar bisa sehat, dan memberikan tingkat produktivitas serta bisa tahan terhadap adanya serangan hama dan penyakit.

Penggunaan tenaga kerja dalam proses penanaman hingga proses pemanenan padi di Desa Kerta Buana ini sudah sesuai dengan kebutuhan yang dibutuhkan dalam proses penanaman hingga proses pemanenan. Sehingga tidak menyebabkan tingginya jumlah biaya yang dikeluarkan dalam proses tersebut. Jadi agar tidak lebih menggunakan tenaga kerja yang berlebih harus bisa mengefesienkan waktu semaksimal mungkin dan jumlah tenaga kerja harus sudah sesuai dengan pekerjaan yang dilakukan, agar jumlah pengeluaran menjadi lebih efisien.

\section{Produksi}

Produksi adalah suatu kegiatan untuk menghasilkan atau menambah nilai guna terhadap suatu barang atau jasa (Gunawan, 2018). Produksi usahatani tanaman padi sawah adalah salah satu semua kegiatan yang dilakukan oleh semua petani padi sawah 
ISSN 2354-7251 (print)

yang ada di Desa Kerta Buana agar dapat mengahasilkan dan mendapatkan nilai guna bagi tanaman padi yang ada di Desa Kerta Buana. Bagi semua responden jumlah produksi yang banyak dipengaruhi oleh luas lahan dan perawatan dalam pengolahan lahan kemudian dalam pemberian pestisida juga sangat berpengaruh. Adapun jumlah produksi dari jumlah keseluruhan 40 responden. Untuk 15 responden sekitar tambang dapat menghasilkan jumlah produksinya memiliki rata-rata sebesar $2.090,00 \mathrm{~kg} \mathrm{mt}^{-1}$ dan setelah di konversikan menjadi memiliki jumlah beras dengan rata-rata yang dihasilkan sebesar $1.341,78 \mathrm{~kg}$. Kemudian untuk 25 responden bukan sekitar tambang memiliki penghasilan dari jumlah produksinya sebesar $3.476,00 \mathrm{~kg} \mathrm{mt}^{-1}$ setelah dikonversikan ke beras memiliki jumlah rata-rata sebesar $2.231,59 \mathrm{~kg}$. Jadi dapat dilihat rincian total produksi .

Tabel 2. Rincian total produksi oleh responden padi sawah sekitar dan bukan sekitar tambang batubara.

\begin{tabular}{lcc}
\hline Padi sawah & \multicolumn{2}{c}{ Produksi $\left(\mathrm{kg} \mathrm{mt}^{-1}\right)$} \\
\cline { 2 - 3 } Sekitar tambang & Jumlah & Rata-rata \\
Bukan sekitar tambang & $86.350,00$ & $2.090,00$ \\
Sumber : Data Primer (Diolah),2019 & & $3.476,00$ \\
\hline
\end{tabular}

Jumlah produksi yang berbeda di akibatkan jumlah luas lahan dan lokasi lahan yang berbeda, untuk harga jual beras cenderung berbeda namun harga beras di Desa tersebut adalah sebesar Rp10.000,00 $\mathrm{kg}^{-1}$. Untuk meningkatkan produksi dan penerimaan adalah dengan cara meningkatkan harga jual petani dan meningkatan hasil produksi yang ada di petani saat ini, kemudian untuk cara yang dilakukan petani adalah meningkatkan hasil produksi dengan cara pemeliharaan penanaman secara teratur seperti pemupukan, pengendalian hama, dan pemeliharaan lainnya sehingga tanaman dapat tumbuh dengan baik.

Produksi yang di peroleh responden usahatani padi sawah di sekitar dan bukan sekitar tambang batubara memiliki perbedaan pada produktifitas yang dipengaruhi oleh kesuburan tanah, yang mengalami dampak dari aliran sungai yang terkena limbah batubara yang masuk di area persawahan yang menyebabkan tinggi nya $\mathrm{PH}$ pada tanah, proses pertumbuhan tanaman yang kurang maksimal, menghilang nya usur hara pada tanah sehingga petani mengeluarkan biaya lebih untuk meningkatkan produksi pada tanaman padi. Sedangkan untuk kualitas tidak begitu berbeda dengan usahatani di sekitar dan bukan sekitar tambang batubara.

Hasil produksi pada penelitian ini lebih kecil jika dibandingkan dengan hasil penelitian Margi dan Siti (2016) yang melakukan penelitian di Desa Kota Bangun, yaitu nilai produksi sebesar $250.220 \mathrm{~kg} \mathrm{mt}^{-1}$ atau rata-rata sebesar $6.256 \mathrm{~kg}$ responden-1 $\mathrm{mt}^{-1}$. Hasil penelitian ini sebanding dengan hasil penelitian oleh Aris Setyawan (2008) yang menunjukkan hasil produksi usahatani Padi sawah relatif lebih besar dibandingkan lahan 
tegalan. Namun, jika dilihat dari struktur biaya, biaya usahatani baik biaya tunai maupun biaya yang diperhitungkan di lahan sawah relatif lebih besar dibandingkan lahan tegalan. Hal ini disebabkan pemakaian tenaga kerja baik tenaga kerja dalam keluarga maupun tenaga kerja luar keluarga di lahan sawah relatif lebih besar dibandingkan lahan tegalan.

\section{Penerimaan}

Penerimaan merupakan hasil dari kali total produksi dengan harga jual beras produksi tersebut, dengan harga jual beras ada saat ini memiliki harga sebesar Rp10.000,00 $\mathrm{kg}^{-1}$. Kemudian jumlah penerimaan dari petani padi sawah sekitar tambang sebanyak 15 responden adalah sebesar Rp201.267.000,00 $\mathrm{mt}^{-1}$ dengan jumlah rata-rata sebesar Rp13.417.800,00 $\mathrm{mt}^{-1}$ sedangkan untuk jumlah penerimaan dari 25 responden padi sawah bukan sekitar tambang sebesar Rp557.898.000,00 $\mathrm{mt}^{-1}$ dengan rata- rata sebesar Rp22.315.920,00 $\mathrm{mt}^{-1}$. Hasil penerimaan pada penelitian ini masih lebih kecil jika dibandingkan hasil penelitian Lusmi (2013) yang melakukan penelitian di Desa Penyinggahan Kabupaten Kutai Barat yaitu sebesar Rp507.550.000,00 $\mathrm{mt}^{-1}$ atau rata-rata per responden Rp24.169.047,62 $\mathrm{mt}^{-1}$.

Besarnya penerimaan yang dihasilkan oleh petani padi sawah di sekitar dan bukan sekitar tambang batubara dipengaruhi hasil panen. Masing-masing petani penerimaannya berbeda, perbedaan ini disebabkan karena hasil panen yang diperoleh. dari proses penanaman hingga panen adalah sangat bagus apabila dalam proses mulai dari perkecambahan sudah sesuai dengan anjuran yang diberikan atau memilih jenis benih yang baik maka akan memperoleh hasil yang maksimal dan kualitas padi di peroleh dapat menentukan tingkat harga di pasaran yang ada saat ini. Jadi untuk pengelolaan pasca panen harus di perhatikan dalam proses penyimpanan tidak sembarangan. Jadi untuk pasca panen sendiri dalam proses penjualan harus sesuai dengan kondisi pasar yang ada dan di jual pada saat harga pembeli naik. Sehinggga dapat meningkatkan pemasukan dari hasil penjualan padi yang ada pada saat itu dan bisa mendapatkan keuntungan utntuk petani itu sendiri.

\section{Pendapatan}

Pendapatan merupakan selisih antara penerimaan dengan jumlah keseluruhan biaya produksi yang telah dikeluarkan selama kegiatan usahatani yang sedang berlangsung. Adapun jumlah pendapatan dari 15 responden padi sawah sekitar tambang batubara adalah Rp54.864.933,33 $\mathrm{mt}^{-1}$ dengan jumlah rata- rata sebesar Rp3.657.662,22 $\mathrm{mt}^{-1}$ kemudian untuk jumlah pendapatan sebanyak 25 responden bukan sekitar tambang batubara sebesar Rp236.748.258,33 $\mathrm{mt}^{-1}$ sedangkan rata- rata Rp9.469.930,33 $\mathrm{mt}^{-1}$. Pendapatan yang diperoleh berbeda-beda dikarenakan luas lahan yang diusahakan dan keberhasilan dari usahatani yang dilakukan oleh responden pun berbeda-beda. 
ISSN 2354-7251 (print)

Tabel 3. Rekapitulasi pendapatan responden padi sawah sekitar dan bukan sekitar tambang batubara di Desa Kerta Buana

\begin{tabular}{lrr}
\hline Keterangan & \multicolumn{2}{c}{ Jumlah } \\
\cline { 2 - 3 } & Sekitar tambang $(0,75 \mathrm{ha})$ & \multicolumn{1}{c}{ Bukan sekitar tambang $(1,08 \mathrm{ha})$} \\
\hline Harga Jual $\left(\mathrm{Rp} \mathrm{kg}^{-1}\right)$ & $10.000,00$ & $10.000,00$ \\
Penerimaan $\left(\mathrm{Rp} \mathrm{mt}^{-1}\right)$ & $201.267 .000,00$ & $557.898 .000,00$ \\
Produksi $\left(\mathrm{kg} \mathrm{mt}^{-1}\right)$ & $31.350,00$ & $86.900,00$ \\
Biaya Produksi $\left(\mathrm{Rp} \mathrm{mt}^{-1}\right)$ & $146.402 .066,67$ & $321.149 .741,67$ \\
Pendapatan (Rp mt & & $236.748 .258,33$
\end{tabular}

Sumber : Data Primer (Diolah),2019

Pendapatan dipengaruhi oleh biaya produksi yang dikeluarkan oleh petani padi sawah di sekitar dan bukan sekitar tambang batubara. Perbedaan pendapatan yang diperoleh masing-masing petani padi sawah di sekitar dan bukan sekitar tambang batubara dipengaruhi oleh perbedaan besarnya jumlah gabah yang dihasilkan dan jumlah biaya yang dikeluarkan untuk usahatani padi sawah. Hal ini dikarenakan usahatani padi sawah di sekitar dan bukan sekitar tambang batubara hanya dijadikan usaha sampingan oleh sebagian besar petani.

Nilai pendapatan dalam penelitian ini lebih kecil dari hasil penelitian Pinto Rukmu Handayani (2016) dalam penelitian Analisis Pendapatan Usaha Tani padi di Desa Sumber Sari Kecamatan Loa Kulu Kabupaten Kutai Kartanegara.rata-rata pendapatan usaha padi sawah di desa sumber sari kecamatan loa kulu pada satu musim tanam sebesar $\mathrm{Rp} 4.043 .000$ per rata rata luas lahan 0,5 ha.

\section{R/C Rasio}

R/C Rasio adalah salah satu konsep yang di gunakan untuk menentukan keuntungan suatu usaha. Hasil perhitungan menunjukkan rata-rata R/C Rasio dari usahatani padi sawah yang ada di Desa Kerta Buana sekitar tambang adalah 1,37 artinya usahatani padi sawah sekitar tambang batu bara baik untuk di budidayakan. Sedangkan untuk usahatani padi sawah bukan sekitar tambang menunjukkan nilai R/C Rasio adalah sebesar 1,74 artinya usahatani padi sawah sekitar tambang batu bara baik untuk di budidayakan.

Tabel 4. Rata-rata perbandingan R/C Rasio usahatani padi sawah di sekitar tambang dan bukan sekitar tambang

\begin{tabular}{|c|c|c|c|c|}
\hline \multirow{2}{*}{ Lokasi } & \multicolumn{4}{|c|}{ Luas lahan rata Rata-rata total penerimaan Rata-rata total biaya $R / c$ Rasio } \\
\hline & (ha) & $\left(\mathrm{Rp} \mathrm{Mt}^{-1}\right)$ & $\left(\mathrm{Rp} \mathrm{Mt}^{-1}\right)$ & \\
\hline Sekitar tambang & 0.75 & $13.417 .800,00$ & $9.760 .137,78$ & 1,37 \\
\hline Bukan sekitar tambang & 1.08 & $22.315 .920,00$ & $12.845 .989,67$ & 1,74 \\
\hline
\end{tabular}

Sumber: Data Primer (Diolah), 2019

Hasil perhitungan R/C Rasio menunjukkan bahwa padi sawah bukan sekitar tambang lebih baik untuk di budidayakan karena lebih tinggi produktifitas nya dan lebih kecil biaya produksi di bandingkan dengan sekitar tambang batubara. Jadi bisa dikatakan 
untuk petani bukan sekitar tambang lebih baik untuk dilakukan budidaya secara terus karena biaya produksi lebih kecil dan penggunaan pupuk, pestisida yg lebih dikit serta mendapatkan tingkat keuntungan yang menunjukkan sangat baik bagi petani yang ada di Desa Kerta Buana pada saat ini. Hasil penelitian ini sejalan dengan hasil penelitian oleh Aris Setyawan (2008) yang menunjukkan nilai R/C rasio usahatani padi lahan sawah maupun lahan tegalan menguntungkan ( rasio $R / C>1$ ).

\section{Hasil Uji T}

Hasil uji t yang telah dilakukan untuk mendapatkan tingkat pendapatan usahatani padi sawah sekitar dan usahatani padi sawah bukan sekitar tambang yaitu thitung $_{\text {sebesar }}$ 3,525 sedangkan $t$ tabel $(0,05)$ sebesar 2,024 maka $t$ hitung $>t$ tabel $(3,525>2,024)$ yang berarti bahwa hipotesis Ho ditolak dan hipotesis Ha diterima. Dengan demikian pada $\alpha=$ 0,05 terdapat perbedaan pendapatan usahatani padi sawah sekitar tambang dan bukan sekitar tambang batubara secara nyata bisa dikatakan signifikan.

Upaya yang dilakukan petani untuk memperoleh hasil yang maksimal sudah dilakukan oleh petani di Desa Kerta Buana melakukan upaya meningkatkan pemeliharaan dan perawatan. Penggunaan sarana produksi juga sangat penting karena dapat mempengaruhi besar kecilnya pendapatan yang diperoleh oleh semua petani yang ada di Desa Kerta Buana. Sarana produksi seperti pembelian lahan, penggunaan benih, penggunaan pupuk, pemberian pestisida, pemakaian alat, dan penggunaan tenaga kerja.

\section{Kesimpulan}

Biaya produksi rata-rata padi sawah di sekitar tambang batubara di Desa Kerta Buana, Kecamatan Tenggarong Seberang dengan rata-rata luas lahan sebesar 0,75 ha adalah Rp9.760.137,78 $\mathrm{mt}^{-1}$, sedangkan rata-rata biaya produksi padi sawah bukan sekitar tambang dengan luas lahan rata-rata 1,08 ha sebesar $\mathrm{Rp} 12.845 .989,67 \mathrm{mt}^{-1}$. Penerimaan rata-rata yang diperoleh petani di sekitar tambang batubara sebesar Rp13.417.800,00 $\mathrm{mt}^{-1}$ sedangkan pendapatan yang diperoleh sebesar Rp3.657.662,22 $\mathrm{mt}^{-1}$. Penerimaan rata-rata yang diperoleh petani di bukan sekitar tambang sebesar Rp22.315.920,00 $\mathrm{mt}^{-1}$, sedangkan pendapatan rata-rata yang diperoleh sebesar Rp9.469.930,33 $\mathrm{mt}^{-1}$. Keuntungan usahatani padi sawah sekitar dan bukan sekitar tambang batubara di Desa Kerta Buana menguntungkan, dengan nilai R/C Rasio maka di hasilkan nilai $\mathrm{R} / \mathrm{C}$ rata- rata sekitar tambang 1,37 dan bukan tambang 1,74. Pendapatan usahatani padi sawah sekitar tambang berbeda secara signifikan dibandingkan dengan pendapatan usahatani padi sawah bukan sekitar tambang yang ada di Desa Kerta Buana Kecamatan Tenggarong Seberang. Hal ini dikarenakan perbedaan produksi yang dihasilkan dan biaya yang dikeluarkan. Sehingga disarankan kepada petani responden untuk berusahatani di lahan bukan sekitar tambang batubara. 


\section{Daftar Pustaka}

Amaliawati, L. dan Murni, A. (2014). Ekonomika Mikro. (Edisi Revisi, Jilid 2). Bandung: Refika Aditama.

Aris, S. (2008). Analisis Efisiensi Produksi dan Pendapatan Usahatani Jagung (Studi Kasus di Desa Beketel, Kecamatan Kayen, Kabupaten Pati, Propinsi Jawa Tengah). Skripsi. Institut Pertanian Bogor. Bogor.

Bangun, W. (2007). Teori Ekonomi Mikro. (Edisi 1, Jilid 22). Bandung: Refika Aditama.

BPS Republik Indonesia. (2018). Produksi Tanaman Padi Indonesia, 2018, http:// www.bps.go.id [17 april 2019]

BPS Kalimantan Timur. (2018). Dalam Angka 2018. Provinsi Kalimantan Timur. Samarinda: BPS Kota Samarinda.

BPS Kabupaten Kutai Kartanegara. (2016). Kecamatan Tenggarong Seberang Dalam Angka 2007, 2011, 2016. Provinsi Kalimantan Timur. Samarinda.

Gunawan, F. (2018). Pengaruh Penggunaan Faktor Produksi Terhadap Produksi Padi Di Desa Baruga Kabupaten Bone. Jurnal Pertanian Vol 1(1) : 1-15

Hernanto, F. (2003). IImu Usaha Tani. Jakarta: Penebar Sewadaya.

Lusmi. (2013). Analisis Pendapatan Usahatani Padi Sawah (Oryza sativa L.) di Desa Penyinggahan Ilir Kecamatan Penyinggahan Kabupaten Kutai Barat. Jurnal EPP 10(1) : 11-19

Margi, T. dan Siti Balkis (2016). Analisis Pendapatan dan Efisiensi Usahatani Padi Sawah Di Desa Kota Bangun Kecamatan Kota Bangun. Jurnal ZIRAA'AH 41(1) : 72-77

Pinto Rukmu Handayani. (2016). Analisis Pendapatan Usaha Tani Padi di Desa Sumber Sari Kecamatan Loa Kulu Kabupaten Kutai Kartanegara. Skripsi.

Pracoyo, T.K. (2006). Aspek Dasar Ekonomi Mikro. (Edisi 1, Jilid 1). Jakarta: PT Grasindo.

Prasetyo,B. \& Jannah, M,L. (2006) Metode Penelitian Kuantitatif. Jakarta: Raja Grafindo Persada.

Desa Kerta Buana Tenggarong Seberang. (2017). Profil Desa. Desa Kerta Buana Tenggarong Seberang, Kutai Kartangara.

Sugiyono. (2010). Metode Penelitian kuantitatif Kualitatif dan R\&D. Bandung: Penerbit CV Alfabeta. 